\title{
LEADING CHANGE: CONVINCING PEOPLE AGAINST THE STATUS QUO
}

\author{
Gerald E. Evans ${ }^{1}{ }^{*}$, Michael G. Evans ${ }^{2}$ \\ ${ }^{1}$ University of Montana, Missoula, College of Business, United States, ${ }^{2}$ University College, Center for Sports Studies, \\ Dublin, Ireland \\ "jerry.evans@business.umt.edu, mgordonevans@gmail.com
}

Article History: Received on $02^{\text {nd }}$ February, Revised on $30^{\text {th }}$ April, Published on $20^{\text {th }}$ July 2019

\begin{abstract}
Purpose: The purpose of this study is to investigate resistance to change. This is a well-documented phenomenon in the change literature. Overcoming this resistance is a critical component to effective change leadership.

Methodology: A structured interview technique was employed using a survey instrument that guided the interview process. Interviews were completed with 89 individuals. A snowball sampling technique was employed beginning with 30 undergraduate students who each completed the interview.
\end{abstract}

Main Findings: This research indicates that individuals who are dissatisfied with the status quo are less likely to resist change. Individuals who perceived that the current status served them well and met their current needs were less likely to embrace or support proposed changes to the status quo. This perception demonstrates risk aversion to potential losses. Conversely, individuals who perceived that the current state did not serve them well or meet their current needs and interests were more likely to embrace and support proposed changes to the status quo demonstrating risk - seeking in the face of potential gains.

Implications: The results can be applied as an effective method for moving people through the change process by convincing them that the current situation has low utility.

Novelty: This paper is one of only a few instances where Prospect Theory and loss aversion has been linked to resistance to change.

Key Words: Change Leadership, Resistance to Change, Leadership, Prospect Theory.

\section{BACKGROUND/OBJECTIVES AND GOALS}

Resistance to change is a well-documented phenomenon in the change literature from both a behavioural Vargo and Ringdahl (2015) and process and outcome perspective (Van K nippenberg et al, 2006). Overcoming this resistance is a critical component to effective change leadership Bass (1985). The current research indicates that individuals who are dissatisfied with the status quo are less likely to resist change. Individuals who perceived that the current status served them well and met their current needs were less likely to embrace or support proposed changes to the status quo. This perception demonstrates risk aversion to potential losses. Conversely, individuals who perceived that the current state did not serve them well or meet their current needs and interests were more likely to embrace and support proposed changes to the status quo demonstrating risk -seeking in the face of potential gains. The results suggest that an effective method for moving people through the change process is to convince them that the current situation has low utility.

A significant literature exists on the topic of change and change management (Brisson-Banks, 2010) and leadership style Holten and Brenner (2015). Beer and Nohria (2000) discussed the two major theories of organizational change that are driven by economic consideration (Theory E) and by organizational capability (Theory $\mathrm{O}$ ). These approaches to change are often unsuccessful and create significant tension within the organization due to resistance to change. This resistance has been analysed by Kegan and Lahey (2001) using the idea of competing commitment. People do not change because they are more committed to aspects of the status quo. Unfortunately, the primary theoretical foundation is behavioural involving conditional and unconditional reinforces Vargo and Ringdahl (2015) which has limited use for leaders. Similarly, the research on individual change in the context of coaching and feedback has limited application to organizational change. (See Carpentier and Mageau, 2013, 2 014, and 2016) Cummings and Worley (2003) wrote extensively on change within the context of organizational development.

Three components of resistance to change in organizations has been investigated by Garcia-Cabrera and Hernandez (2014) and by Ford et al. (2008), but without a convincing theoretical foundation. A more theoretically grounded approach to 
resistance to change was proposed by Martin (2017) in her study of resistance to telework using Prospect Theory Kahneman and Tversky (1979). Specifically, within Prospect Theory, the concept of loss aversion motivates people to place more weight on the prospects of certain or probable loss when evaluating a decision making them risk averse when facing losses Kahneman et al. (1991). This leads to the endowment effect in which things that have high utility to an individual become more valuable when they are possessed or owned. Then, the price for giving up these possessions is higher than the cost one would pay to acquire them.

Prospect Theory describes the behaviour wherein individuals are risk averse to the prospects of losing something that they have. The higher the utility of that which is possessed, the more risk averse they become to the prospects of losing it. We tend to hang on to things that we possess and have high utility; we will resist the prospect of losing these possessed things. Conversely, Prospect Theory describes behaviour that is more risk tolerant when facing the prospect of gains. If one does not have something that has high utility, they tend to take greater risks to gain or possess it. We tend to seek high utility things that we do not possess; we take greater chances to gain something of high utility that we do not already have.

Prospect Theory is well documented and is a descriptive theory of how people actually behave. Its application to economics was a significant contribution to the science of economics and is a key component of behavioural economics Kahneman et al. (1991). Daniel Kahneman was awarded the Nobel Prize in Economic Sciences in 2002 for his development of Prospect Theory. Prospect Theory provides a theoretically rigorous and empirically documented explanation for resistance to change in the areas of organizational and public policy as well as personal lifestyle changes.

It has been demonstrated Evans and Evans (2018) that if change is proposed to an organizational or public policy that currently has high utility for an individual, they will resist changes to that policy or operating scheme. High utility in this instance would be a policy that has a high impact on the individual and is serving their needs well. The status quo is working, so let's keep it. Prospect Theory predicts that an individual in this state of high impact and high alignment with current values and needs would resist changes to the policy reasoning that any change would be for the worse. On the other hand, if change is proposed to a policy that currently has low utility for an individual, high impact but low alignment with current needs and values, an individual would be more risk tolerant, reasoning that any change would likely be an improvement to the current situation. The status quo is not working so let's change it.

Martin (2017) suggested that effective change leadership required individuals be convinced against the status quo. The current research attempts to test that supposition. We predict that when confronted with a policy that has high impact and high utility, individuals will judge that proposed changes will likely be detrimental to them and to other people. Furthermore, when confronted with a policy that has high impact and low utility, individuals will judge that proposed changes will likely be beneficial to them and to other people.

Specifically, we hypothesize that individuals who are less satisfied with the status quo will be more likely to embrace proposed change than those individuals who are more satisfied with the status quo. Additionally, we hypothesize that individuals who are less satisfied with the status quo will deem the benefit of the impending change more favourably than those individuals who are more satisfied with the status quo. Finally, we hypothesize that individuals who are less satisfied with the status quo will be more likely to support the proposed change than individuals who are more satisfied with the status quo.

\section{METHODS}

2.1 Participants: Interviews were completed with 89 individuals. A snowball sampling technique was employed beginning with 30 undergraduate students who each completed the interview (See Malhotra, 2010). Each of these students found two other willing participants to participate in the interview process. Half of the participants reported their gender as male and half reported their gender as female. One participant did not report their gender.

2.2 Interview Instrument and Procedure : A structured interview technique was employed using a survey instrument that guided the interview process (Dillman, 2000). The purpose of the first part of the interview was to identify areas of current policy that had a high impact on the participant. High impact was defined as having considerable influence on the participant's life and well- being either economically, socially, physically or in some other manner identified by the participant. Policy areas that were addressed included tax policy, healthcare, local planning, financial aid, food production, environmental policy, animal rights, immigration, housing, banking, investment, business formation, criminal justice, and social welfare. Respondents could also identify additional areas of interest or concern. This initial stage of the interview was designed to identify areas of policy that had a high impact on participants. 
Once high impact areas of policy were identified, the second stage of the interview was to identify one area of policy that was well aligned with the participant's interests and values. This high alignment was defined as being congruent with the participant's political or social philosophy, or that the current policy benefited them economically, socially, physically, or psychologically. The goal was for each participant to identify a high impact, high alignment area of policy; a policy that highly impacted them in a positive manner.

The same process was employed to identify an area of policy that had high impact on the participants, but low alignment with the participant's interests and values. This low alignment was defined as being incongruent with the participant's political or social philosophy, or that the current policy worked to their detriment economically, socially, physically, or psychologically. The goal was for each participant to identify a high impact, low alignment area of policy; a policy that highly impacted them in a negative manner.

The goal at the end of this part of the interview was to have each participant thinking about two areas of public policy that highly impacted them; one that impacted them positively, and one that impacted them negatively. Each participant may have ended up with different areas of public policy in mind, but the goal was to have them thinking about policies that really impacted them in a positive and negative manner.

The next stage of the interview introduced the prospect of change. Depending on the areas of policy that were identified by individual participant s, they were told that the policy makers were embarking on a process to change the system. The exact nature of the change was not specified. The goal here was to have participants thinking about these high impact public policy areas being changed by the relevant policy makers. Then participants were asked four questions about the possible impact of the impending change on them.

The first question was the likelihood that the change would benefit them personally. Responses were recorded on a 10-point scale with 1 being that it would be highly unlikely that the change would be better for them personally, and 10 being that it would be highly likely that the change would be better for them personally. The second question asked if the impending change would be better overall for people in general. A similar 10-point scale was employed with 1 being highly unlikely that the change would be better overall for people in general, and 10 being highly likely that the change would be better overall for people in general. The third question asked about the likelihood that they personally would support the procedure used in changing the area of public policy, and the fourth question asked about the likelihood that they would support the specific change th at resulted from the process. Both of these questions used a similarly worded 10-point scale with 1 being highly unlikely to support the process or the specific change, and 10 being highly likely that they would support the process or the specific change. This part of the interview attempted to assess and record the degree to which they support the change and change process or resisted the change and process.

The final part of the interview collected information on gender, age, and income as well as information on participants' overall attitude toward change and their level of activity in public policy. The questions on attitude toward change and level of activity in public policy were scored on a 10-point scale. For attitude toward change, participants were asked "How much do you like change?" and their responses were recorded on the 10-point scale with 1 being "I do not like changes", and 10 being, "I really like changes". The responses on involvement in public policy were recorded on a 10-point scale with 1 being "I'm not involved at all in public policy", and 10 being, "I am highly involved in public policy". The actual nature of respondents' public policy involvement was also recorded.

\section{RESULTS}

To test the hypotheses that participants would judge impending change in an area of policy that had high impact and high alignment as detrimental, while change in an area of policy that had high impact and low alignment would work to their advantage, a series of paired t-tests were conducted on the three questions concerning change. For each question, the specific alternate hypothesis was that participants would rate the impending change of the high impact, low alignment case as more beneficial than the high impact, high alignment case. For each of the three questions, the null hypothesis was rejected in favour of the alternate hypothesis.

For the first hypothesis, when asked if an impending change in policy would be better for them personally, respondents who were dissatisfied with the status quo rated the personal benefit of an impending change over two points higher (mean difference $=2.146)$ than for changes in policy for which they were satisfied with the status quo. $\left(\mathrm{t}_{(88)}=5.365, \mathrm{p}<.001\right)$. Table 1 displays the means and standard deviations.

Examining this difference more closely, 92.1 percent of the respondents had a positive difference. This means they rated 
Table 1: Means and Standard Deviations for Hypothesis 1

\begin{tabular}{llllll}
\hline & Satisfied & Dissatisfied & & & \\
Mean & 4.10111 & 6.2472 & & & \\
St. Deviation & 2.48196 & 2.81748 & & & \\
Mean Diff. & & & 2.14609 & $\mathrm{t}_{(88)}=5.365$ & $\mathrm{P}<.001$ \\
\hline
\end{tabular}

the likelihood that an impending change to a policy with which there were dissatisfied would benefit them personally as compared to a change in a policy with which they were satisfied. Respondents were more likely to rate a change as positive for them personally if they were dissatisfied with the status quo.

For the second hypothesis, when asked if the impending change would be better for people overall, respondents who deemed the status quo dissatisfying rated the likelihood that the change would be better almost two points (mean difference $=1.8652)$ than respondents who rated the status quo as satisfying $\left(\mathrm{t}_{(88)}=4.706, \mathrm{p}<.001\right)$. If they were dissatisfied with the current policy, an impending change was viewed as more positive than if they were satisfied with the status quo. Table 2 displays the means and standard deviations.

Table 2: Means and Standard Deviations for Hypothesis 2

\begin{tabular}{llllll}
\hline & Satisfied & Dissatisfied & & & \\
Mean & 4.1573 & 6.0225 & & & \\
St. Deviation & 2.61507 & 2.81626 & & & \\
Mean Diff. & & & 1.8652 & $\mathrm{t}_{(88)}=4.706$ & $\mathrm{P}<.001$ \\
\hline
\end{tabular}

Examining the results more closely, 87.6 percent of the respondents had a positive difference. This means respondents who viewed the status quo as unsatisfactory rated the likelihood that the impending change would be better for people overall higher than for policies that were rated as more satisfying.

For the third hypothesis, when asked if they would support the specifics of the impending change, respondents were more likely to support the change if they rated the status quo unsatisfactory by two points (mean difference $=2.0338$ ) on the scale than if they rated the status quo satisfactory $\left(\mathrm{t}_{(88)}=5.003, \mathrm{p}<.001\right)$. Table 3 displays the means and standard deviations.

Table 3: Means and Standard Deviations for Hypothesis 3

\begin{tabular}{llllll}
\hline & Satisfied & Dissatisfied & & & \\
Mean & 4.4831 & 6.5169 & & & \\
St. Deviation & 2.48684 & 2.67612 & & & \\
Mean Diff. & & & 2.0338 & $\mathrm{t}_{(88)}=5.003$ & $\mathrm{P}<.001$ \\
\hline
\end{tabular}

Examining the results more closely, 87.6 percent of the respondents had a positive difference. This means that if they rated the status quo less positively, the likelihood that they would support the specifics of the impending change were greater than if they rated the status quo more positively. Respondents would embrace the change more readily if they were dissatisfied with the status quo. They were less likely to support the change if they were satisfied with the status quo.

\section{DISCUSSION}

These results provide support for the idea that resistance to change is tied to viewing the status quo as having high utility. Additionally, individuals who viewed the status quo as having low utility were less likely to resist change. Participants in this research were more risk averse at the prospect of change in areas of policy that held high utility for them. If the status quo was working for them, than the proposed changes were judged more likely to be detrimental. When participants contemplated the prospects of change in an area of policy that had lower utility for them, they judged that the change would more likely be beneficial. Thus, effective change leadership requires that individuals become dissatisfied with the status quo. This pattern is consistent with Prospect Theory which predicts that individuals will be risk averse in regard to potential loss and risk seeking in regards to potential gains. 
Moreover, they judged the impending change to be beneficial for people in general if the current policy was viewed negatively for them personally, and they judged the impending change to be detrimental for people in general if the current policy was viewed positively for them personally. Our participants generalized their own prospects to the larger population. Additionally, they would be more likely to support the specific changes if they were dissatisfied with the status quo and less likely to support the changes if they were more satisfied with the status quo.

\section{CONCLUSION}

The insights gained from this study, that support for change is partially determined $\mathrm{d}$ an individual's attitude toward the status quo, can be applied to many areas including organizational leadership and change. Lewin (1947) understood that change begins with unfreezing people from the status quo. Hussain et al. (2017) augmented Lewin's work by adding the role of leadership and employee involvement in the change process. Within the theoretical framework of Prospect Theory, this would mean helping people understand the lack of utility in the status quo, so they could begin to view the change in terms of gains rather than losses. This is part of Kotter (1996) eight-step plan for organizational change. His first step is for leaders to develop a sense of urgency, by pointing out the lack of utility in the status quo and to view change in terms of gains of utility rather than losses. Rogers (2003) work on diffusion of innovation also benefits from the perspective of convincing people against the status quo. Early adopters are individuals who immediately see the innovation in terms of gains in utility and laggards persist in seeing the innovation in terms of loss of the status quo. More rapid acceptance of innovation would occur if the benefits of innovation could be explained in terms of gains in functionality and utility.

This study provides the theoretical foundation, Prospect Theory, for overcoming resistance to change by demonstrating the status quo has low utility. Future research must focus on how convincing people against the status quo must be done. Certainly, in situations like corporate turnarounds, the case for the lack of utility for the status quo is easily made. Other area $\mathrm{s}$ of change leadership may be more nuanced. Changes in organizational or public policy that work for some individuals but work less well for others present challenges for change leadership. How does a leader convince individuals for whom a current policy or situation has high utility that said policy must be changed for some other, higher set of priorities? Clearly the details of such an approach must be established through further research.

\section{ACKNOWLEDGEMENT}

The authors would like to acknowledge the support and encouragement of the Dean and faculty at the College of Business at the University of Montana, and the Centre for Sports Studies at University College, Dublin.

\section{REFERENCES}

Bass, B. M. (1985). Leadership and Performance Beyond Expectations. The Free Press, New York, NY.

Beer, M. and Nohria, N. (2000). Cracking the Code of Change. Harvard Business Review, 78(3):133-141.

Cummings, T. G. and Worley, C. G. (2003). Organizational Development and Change. California. 8th ed.

Evans, G. and Evans, M. (2018). Changing Benefits and Loss Aversion: Lessons from Prospect Theory and Resistance to Change. The Journal of Human Resource and Adult Learning, 14(1):1-6.

Ford, J. D., Ford, L. W., and \&amp; Damelio (2008).

Garcia-Cabrera, A. M. and Hernandez, F. G. (2014). Differentiating the three components of resistance to change: The moderating effect of organization-based self-esteem on the employee involvement-resistance relation. Human Resource Development Quarterly, 25(4):441-467.

Holten, A. and Brenner, S. O. (2015). Leadership style and the process of organizational change. Leadership and Organizational Development Journal, 36(1):2-16.

Hussain, S. T., Lei, S., Akram, T., Haider, M. J., Hussain, S. H., and Ali, M. (2017). Kurt Lewins change model: Acritical review of the role of leadership and employee involvement in organizational change. Journal of Innovation and Knowledge, $7(2)$.

Kahneman, D., Knetsch, J. L., and Thaler, R. (1991). Anomalies: The Endowment Effect, Loss Aversion, and the Status Quo Bias. The Journal of Economic Perspectives, 5(1):193-206.

Kahneman, D. and Tversky, A. (1979). Prospect Theory: An Analysis of Decision Under Risk. Econometrica, 47(2):263292.

Kotter, J. P. (1996). 
Lewin, K. (1947). Frontiers in Group Dynamics: Concept, Method and Reality in Social Science; Social Equilibria and Social Change. Human Relations, 1:5-41.

Martin, B. H. (2017). Unsticking the Status Quo: Strategic Framing Effects on Managerial Mindset, Status Quo Bias and Systematic Resistance to Change. Management Research Review, 40(2):122-141.

Rogers, E. M. (2003). 5th ed.

Vargo, K. K. and Ringdahl, J. E. (2015). An evaluation of resistance to change with unconditioned and conditioned reinforcers. Journal of Applied Behavioral Analysis, 48:643-662. 